\title{
The PhyR homolog RSP_1274 of Rhodobacter sphaeroides is involved in defense of membrane stress and has a moderate effect on RpoE (RSP_1092) activity
}

\author{
Qingfeng $\mathrm{Li}^{1 \dagger}$, Tao Peng ${ }^{1,2+}$ and Gabriele Klug ${ }^{1 *}$ (D)
}

\begin{abstract}
Background: A major role of the PhyR-NepR- $\sigma(E c f G)$ cascade in the general stress response was demonstrated for some bacterial species and considered as conserved in Alphaproteobacteria. The $\sigma(\mathrm{EcfG})$ factor activates its target genes in response to diverse stresses and NepR represents its anti-sigma factor. PhyR comprises a response regulator domain and a sigma factor domain and acts as anti-sigma factor antagonist. The facultative phototrophic alphaproteobacterium Rhodobacter sphaeroides harbours a PhyR homolog in the same genomic context as found in other members of this class.

Results: Our study reveals increased expression of the phyR gene in response to superoxide, singlet oxygen, and diamide and also an effect of PhyR on rpoE expression. RpoE has a central role in mounting the response to singlet oxygen in R. sphaeroides. Despite these findings a mutant lacking PhyR was not significantly impeded in resistance to oxidative stress, heat stress or osmotic stress. However a role of PhyR in membrane stress is demonstrated.

Conclusion: These results support the view that the effect of the PhyR-NepR- $\sigma(E c f G)$ cascade on diverse stress responses varies among members of the Alphaproteobacteria. In the facultative phototroph Rhodobacter sphaeroides PhyR plays no major role in the general stress or the oxidative stress response but rather has a more specialized role in defense of membrane stress.
\end{abstract}

Keywords: Alphaproteobacteria, Rhodobacter sphaeroides, General stress response, Oxidative stress, Membrane stress, PhyR, Alternative sigma factors, Anti sigma factor

\section{Background}

In their natural environment bacteria are exposed to changing conditions, which often cause stress. To survive these conditions they have evolved defense systems that allow adaptation to the changing environment. Many previous studies revealed a big overlap of the responses to a variety of different stress factors, considered as general stress response.

\footnotetext{
* Correspondence: Gabriele.Klug@mikro.bio.uni-giessen.de

${ }^{\dagger}$ Equal contributors

${ }^{1}$ Institut für Mikrobiologie und Molekularbiologie, Interdiziplinäres Forschungszentrum, Justus-Liebig-Universität Giessen, Heinrich-Buff-Ring 26-32, 35392 Giessen, Germany

Full list of author information is available at the end of the article
}

The PhyR-NepR- $\sigma$ (EcfG) cascade was recognized as a core pathway regulating the general stress response in Alphaproteobacteria [1]. PhyR (phyllosphere regulator) was identified as a response regulator essential for plant colonization by Methylobacterium extorquens and promotes resistance to various stresses by controlling stressrelated genes [2,3]. In several Alphaproteobacteria, the $p h y R$ gene is in close proximity to the nepR and ecfG genes [1]. The $\sigma(E c f G)$-orthologous sigma factors RpoE2 (Sinorhizobium meliloti) and SigT (Caulobacter crescentus) induce large regulons in response to various stresses $[4,5]$. In $M$. extorquens, NepR (negative regulator of the PhyR response) and PhyR control the activity of the $\sigma(\mathrm{EcfG})$ 
sigma factor by acting as anti-sigma factor and as antisigma factor antagonist, respectively [6]. In the current model [1] NepR sequesters $\sigma(\mathrm{EcfG})$ under non-stress conditions. Under stress conditions, the response regulator PhyR becomes phosphorylated, interacts with NepR and consequently releases $\sigma(\mathrm{EcfG})$, which in turn associates with RNA polymerase.

Rhodobacter sphaeroides is a facultative phototrophic Alphaproteobacterium, which has been intensively studied in regard to its oxidative stress response, including singlet oxygen stress [7-9]. In photosynthetic bacteria (bacterio-) chlorophylls act as photosensitizers, which generate this harmful oxygen species when light and oxygen are present. The ECF sigma factor RpoE (RSP_1092) plays an important role in the singlet oxygen response of $R$. sphaeroides. Many genes are activated by RpoE [10, 11], however only a small subset directly [11]. Among the genes activated by RpoE is the alternative sigma factor RpoHII, which directly activates a much larger set of genes [12]. The RpoHII regulon has an overlap with the RpoHI regulon [13, 14], both sigma factors also have an important role in the general stress response [15]. Under non-stress conditions, RpoE is sequestered by the anti-sigma factor ChrR [16, 17], which is degraded upon singlet oxygen stress by the proteases DegS and RseP [18]. The RSP_2681 protein was also annotated as RpoE, but shares only $37 \%$ similarity with RSP_1092. No role of RSP_2681 in stress responses was reported to date. ChrR homologs, are also present in some Alphaproteobacteria besides Rhodobacter but lacking in others. While many Alphaproteobacteria harbour the PhyR-NepR- $\sigma$ (EcfG) cascade as well as an RpoE/ ChrR system, others like Methylobacterium extorquens or Brucella melitensis harbour the PhyR-NepR- $\sigma$ (EcfG) cascade but lack a ChrR homolog.

A single PhyR homolog, RSP_1274, is also encoded in the $R$. sphaeroides chromosome and considering its function in other Alphaproteobacteria we hypothesized a function in the oxidative stress response and / or heat shock response in this organism. Our results do not support an important function of PhyR in theses stress responses for this phototrophic bacterium, however we observed an effect on membrane stress.

\section{Methods}

\section{Bacterial strains and growth conditions}

All strains, plasmids, and oligonucleotides used in this study are listed in Additional file 1. Rhodobacter sphaeroides was cultivated at $32{ }^{\circ} \mathrm{C}$ in minimal malate salt medium [19] in $50 \mathrm{ml}$ Erlenmeyer flasks or flat bottles. Aerobic growth conditions with 160 to $180 \mu \mathrm{M}$ dissolved oxygen were established by continuous shaking of $50 \mathrm{ml}$ Erlenmeyer baffled flasks with $20 \mathrm{ml}$ medium at $140 \mathrm{rpm}$ or by gassing air into cultures in flat bottles. For microaerobic growth conditions, Erlenmeyer flasks with a culture volume of $80 \%$ were agitated at $140 \mathrm{rpm}$, resulting in a constant dissolved oxygen concentration of 25 to $30 \mu \mathrm{M}$ during the mid exponential growth phase. Escherichia coli strains were grown in LB medium at $37{ }^{\circ} \mathrm{C}$ with shaking at $180 \mathrm{rpm}$ or on solid growth medium, which contained 1.6\% (w/v) agar. As necessary, antibiotics were added into liquid or solid medium at the following concentration: kanamycin $\left(25 \mu \mathrm{g} \mathrm{ml}{ }^{-1}\right)$; spectinomycin $\left(10 \mu \mathrm{g} \mathrm{ml}^{-1}\right)$; tetracycline $\left(1.5 \mu \mathrm{g} \mathrm{ml}^{-1}\right)$ (for $R$. sphaeroides); trimethoprim $\left(50 \mu \mathrm{g} \mathrm{ml}^{-1}\right)$. Antibiotics were omitted from cultures and agar plates used for $R$. sphaeroides during stress experiments and zone inhibition assay.

\section{Construction of a R. sphaeroides PhyR (RSP_1274) deletion mutant}

Rhodobacter sphaeroides strain $\triangle \mathrm{PhyR}$ was generated by transferring the suicide plasmid pPHU $\Delta$ RSP_1274:Sp into $R$. sphaeroides 2.4.1, and screening for insertion of the spectinomycin resistance cassette into the chromosome by homologous recombination. The suicide plasmid was also transferred to the strains $\Delta \mathrm{ChrR}$ and TF18 (lacks RpoE and ChrR) to create the respective double and triple mutant. Parts of the RSP_1274 gene of $R$. sphaeroides 2.4.1, together with upstream and downstream sequences were amplified by polymerase chain reaction (PCR) using oligonucleotides 1274_for1_KpnI/ 1274_rev2_EcoRI and 1274_for3_EcoRI/1274_rev4_XbaI (Additional file 1: Table S2). The amplified PCR fragments were cloned into the XbaI-EcoRI and EcoRI-KpnI sites of suicide plasmid pPHU281 [20], generating plasmid pPHU $\Delta$ RSP_1274. A $2.2 \mathrm{~kb}$ fragment containing the spectinomycin cassette from pHP45 $\Omega$ [21] was inserted into the EcoRI site of pPHU $\triangle$ RSP_1274 to generate pPHU $\Delta$ RSP_1274:Sp. This plasmid was transferred into E. coli strain S17-I and biparentally conjugated into $R$. sphaeroides 2.4 .1 wild-type strain. Conjugants were selected on malate minimal medium agar plates containing spectinomycin $\left(10 \mu \mathrm{g} \mathrm{ml}^{-1}\right)$ and subsequently tested for tetracycline sensitivity.

\section{RNA extraction, northern blot analysis, and RNAseq}

For Northern blot analysis, samples from stress experiment were collected before $(0 \mathrm{~min})$ and $7 \mathrm{~min}$ after organic peroxide $(360 \mu \mathrm{M}$ of $\mathrm{t}$-Butyl hydroperoxide $(\mathrm{t}-\mathrm{BOOH}))$ stress condition. Total RNA was isolated by the hot phenol method [22]. A total of $10 \mu \mathrm{g}$ RNA was loaded per lane and separated on $10 \%$ polyacrylamide gels containing $7 \mathrm{M}$ urea. RNA was transferred onto Biodyne B $0.45-\mu \mathrm{m}$ membranes (Pall) by semidry electroblotting. For detection of Pos19 (photo-oxidative stress induced sRNA 19), the end-labeled oligonucleotide p-0019 was used. Membranes were exposed on 
phospho imaging screens (Bio-Rad) and analyzed with the Quantity One software (Bio-Rad).

RNAseq and dRNAseq are described in Remes et al. [23]. The RNA-seq data are available at the NCBI Gene Expression Omnibus database under accession number GSE71844.

\section{Quantitative real-time RT-PCR}

The one step Brilliant III Ultra-Fast SYBR ${ }^{\circ}$ QRT-PCR Master Mix Kit (Agilent) was used for reverse transcription followed by PCR as described in the manufacturer's manual. For real-time RT-PCR, a final concentration of $4 \mathrm{ng}^{\mathrm{l}} \mathrm{l}^{-1}$ of total RNA was run in a C1000 Thermal cycler (Bio-Rad) for relative quantification of mRNAs in each of the three independent experiments. Relative expression of target genes was calculated relative to expression of untreated samples and normalized to the housekeeping gene rpoZ according to Pfaffl [24].

\section{$\beta$-galactosidase assay}

$\beta$-galactosidase assays were performed according to the method of Miller [25, 26]. At least three biological repeats were measured. In brief, cultures were inoculated from a single colony into $40 \mathrm{ml}$ minimal salt medium and grown under microaerobic growth condition. Cultures were diluted to an $\mathrm{OD}_{660}$ of 0.2 in a flat bottle and allowed to double once under aerobic growth conditions in darkness. $\beta$-galactosidase activity was measured before $(0 \mathrm{~h}), 1$ and $3 \mathrm{~h}$ under singlet oxygen (high light $880 \mathrm{~W} \mathrm{~m}^{-2}$ and $50 \mathrm{nM}$ methylene blue) and organic peroxide ( $360 \mu \mathrm{M}$ of t-Butyl hydroperoxide $(\mathrm{t}-\mathrm{BOOH}))$ stress.

\section{Zone of inhibition assay}

All strains were grown in minimal salt medium to $\mathrm{OD}_{660}$ of $0.5 .500 \mu \mathrm{l}$ of culture were mixed with $5 \mathrm{ml}$ pre-warmed soft agar and poured on solid minimal salt medium. Disks were placed at the center of plates, $5 \mu \mathrm{l}$ of $10 \mathrm{mM}$ methylene blue, $750 \mathrm{mM} \mathrm{t}-\mathrm{BOOH}, 700 \mathrm{mM}$ diamide or $700 \mathrm{mM}$ paraquat were added on the filter disks. The plates of methylene blue were incubated in the light (60 W lamp), other plates were incubated in the dark. The diameters of growth inhibition areas were measured after incubation at $32{ }^{\circ} \mathrm{C}$ for 3 days [18].

\section{Ultraviolet assay}

All strains were cultured to an $\mathrm{OD}_{660}$ of $0.7-0.8$ and diluted to a final dilution of $0.5 \times 10^{-6} .50 \mu \mathrm{l}$ of the dilution was distributed on four plates. Plates were exposed to Ultraviolet (UV) light of $100 \mathrm{~J} \mathrm{~m}^{-2}(254 \mathrm{~nm})$ and incubated under the indicated temperature in the light or in the dark. The plates incubated in the light overnight were then transferred to the dark. Survival rates of UV exposed cells compared with non-exposed cells were calculated after incubating 3 days in the dark.

\section{Survival assays}

All strains were cultured to an $\mathrm{OD}_{660}$ of 0.5 in microaerobic condition. For spot survival assays, ethanol (12\%), SDS $(0.015 \%)$ and EDTA $(30 \mathrm{mM})$, polymyxin B $(2.5 \mu \mathrm{g} / \mathrm{ml})$ or CCCP $(25 \mu \mathrm{M})$ were added. Growth of viable cells was monitored by spotting $5 \mu$ from consecutive 10-fold dilutions onto agar plates after 30 and 60 min of ethanol, 15 and 30 min of SDS and EDTA. For counting survival cell numbers, cultures treated in the same way or treated for $60 \mathrm{~min}$ with polymyxin $\mathrm{B}$ $(2.5 \mu \mathrm{g} / \mathrm{ml})$, or $60 \mathrm{~min}$ of $\mathrm{CCCP}(25 \mu \mathrm{M})$ were further dilutes $10^{-1}$ to $10^{-6}$.(dependent on the strain) and $50 \mu \mathrm{l}$ were spread on the plate. Colonies were counted after three days incubation at $32{ }^{\circ} \mathrm{C}$ in the dark.

\section{Results}

Genomic context of the phyR gene RSP_1274

PhyR consisting of an amino terminal effector domain and a carboxy-terminal domain, was described first in Methylobacterium extorquens AM1 as a protein that regulates genes expression involved in general stress response. The amino terminal effector domain is a conserved general stress regulator in Alphaproteobacteria orthologous to sigma factors SigT of Caulobacter crescentus [4] and RpoE2 of Sinorhizobium meliloti [27]. The carboxy-terminal domain is also conserved. Phosphorylation of an aspartate in this domain leads to a conformational change which subsequently activates the effector domain [28]. Gene RSP_1274 of R. sphaeroides encodes a protein that shares $50 \%, 49 \%, 49 \%$ and $48 \%$ identity with the PhyR proteins from Sinorhizobium meliloti, Methylobacterium extorquens AM1, Bradyrhizobium japonicum and Caulobacter crescentus, respectively. As found for several other Alphaproteobacteria [1], an RNA polymerase sigma factor (RSP_1272) and a sensor histidine kinase (RSP_1271) are encoded upstream of the phyR gene (RSP_1274) on the opposite strand (Fig. 1). The RSP_1272 gene product shares $45 \%$ identity with RpoE2 from S. meliloti and $42 \%$ identity with SigT from C. crescentus. Other bacteria harbour the gene for the 61 aa NepR protein between the ecfG gene and the phyR gene. In this position $R$. sphaeroides encodes a 68 aa protein with $25 \%$ identity to NepR. Downstream of phyR a protein of the Crp-Fnr family is encoded. The gene arrangement for $R$. sphaeroides and selected Alphaproteobacteria is shown in Fig. 1.

Differential RNA sequencing (dRNAseq) revealed the transcriptional organization for these genes. This method compares RNA samples, which were treated with terminal exonuclease with untreated samples and thus discriminates between RNA $5^{\prime}$ ends with triphosphate (TSS, 


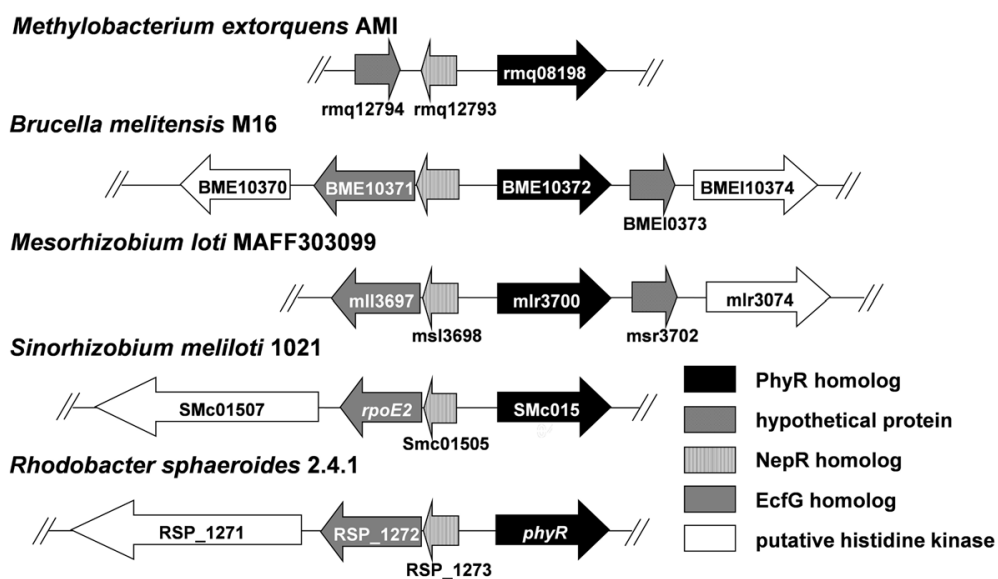

Fig. 1 Genetic organization of the phyR locus in different Alphaproteobacteria

transcriptional start sites) and RNA with monophosphate at the 5' end (processing sites) [29]. The data strongly suggest that RSP_1273 and RSP_1272 are transcribed together from a promoter which is located upstream of RSP_1273, opposite to the coding region of phyR (Additional file 2). Another TSS seems to be present for RSP_1271, however slightly downstream of the ATG start codon of the annotated protein. This ATG overlaps with the TAG terminator codon of RSP_1272 suggesting translational coupling.

\section{PhyR affects the resistance of $R$. sphaeroides to membrane stress but not to oxidative stress}

In order to test the function of the PhyR homolog in $R$. sphaeroides stress response, we constructed a deletion strain which lacks the $p h y R$ gene and has a spectinomycin cassette inserted instead the doubling time of strain. $\triangle$ PhyR did not differ from the doubling time of the parental wild type 2.4.1 in aerobic conditions or during exposure to singlet oxygen (data not shown). There was also no difference in doubling time during osmotic stress $(200 \mathrm{mM} \mathrm{NaCl})$ in aerobic growth condition. Wild type and mutant strain also showed identical absorption spectra excluding an effect of PhyR on photosynthesis gene expression (data not shown).

Zone inhibition assays revealed no difference in resistance to singlet oxygen, $\mathrm{t}-\mathrm{BOOH}$, superoxide, or diamide between wild type and mutant (Fig. 2). Reaction of singlet oxygen with proteins, lipids and photopigments results in both direct damage and the formation of longlived reactive organic peroxides. $\mathrm{t}-\mathrm{BOOH}$ is used as model organic peroxide in our assays. In the same experiments we observed significantly increased resistance of a mutant lacking ChrR (RSP_1093) and decreased resistance in a mutant lacking RpoE (RSP_1092) and ChrR (strain TF18) against these stress factors (Fig. 2). Strains lacking ChrR and PhyR together or lacking RpoE/ChrR/
PhyR showed the same stress resistance as the parental strains harbouring PhyR (Fig. 2). Thus an additional lack of PhyR did not alter the effects of higher RpoE activity (strain $\triangle$ ChrR) or a lack of RpoE (strain TF18).

Since PhyR-dependent signaling also contributes to the heat stress response in other bacteria [6], we tested the effect of the deletion on growth at elevated temperature. Plates were incubated at $42{ }^{\circ} \mathrm{C}$ for $24 \mathrm{~h}$ after streaking and further incubation was at $32{ }^{\circ} \mathrm{C}$ for $72 \mathrm{~h}$. These plates were compared to plates permanently grown at $32{ }^{\circ} \mathrm{C}$. As previously described, we observed a clear growth defect of strains lacking RpoHI or RpoHI and RpoHII after heat stress [13]. Both sigma factors are known to be involved in the heat shock response of $R$. sphaeroides [12, 14]. There was no significant effect of elevated temperature on growth of the strain lacking PhyR (Additional file 3).

When $R$. sphaeroides cells were exposed to UV light and kept in the dark, the survival rate of the mutant strain was significantly lower than that of the wild type. When the cells were incubated in the light allowing photoreactivation, no difference in survival rates was observed for the two strains (Fig. 3). This suggests that PhyR does not affect the photolyase activity of $R$. sphaeroides $[30,31]$, but rather processes for UV repair that are light-independent.

Additional experiments addressed the resistance of $R$. sphaeroides wild type and mutant to membrane stress. Survival was monitored by spot plating assays following treatment with SDS and EDTA or treatment with ethanol. After 15 min of treatment with $0.015 \%$ SDS and $30 \mathrm{mM}$ EDTA survival of the wild type was much better than that of the mutant (Additional file 4A) indicating a role of the PhyR homolog in defense of membrane stress. $30 \mathrm{~min}$ or $60 \mathrm{~min}$ after treatment with ethanol the wild type showed slightly better survival than the $\triangle$ PhyR mutant (Additional file 4B). When the PhyR 


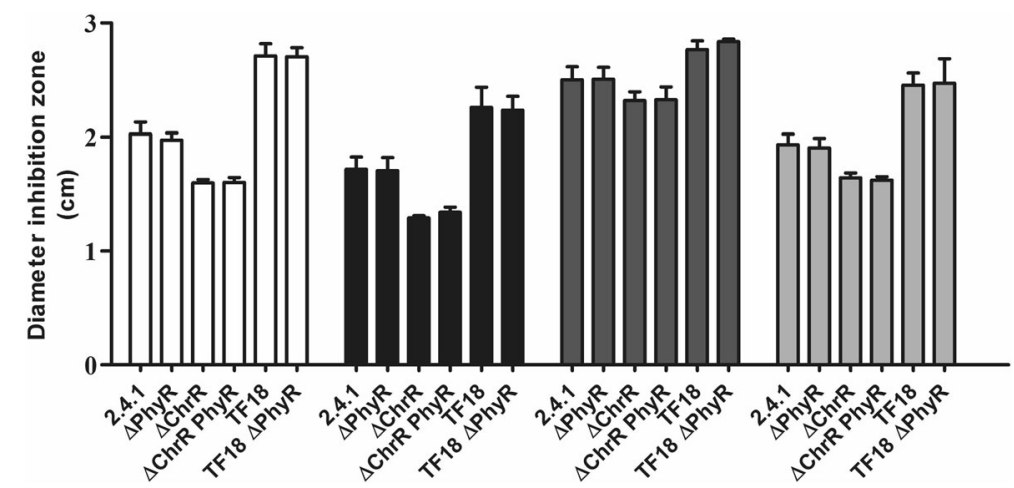

Fig. 2 Inhibition of growth of the R. sphaeroides wild type strain 2.4 .1 and of mutants lacking the phyR or chrR gene or chrR and rpoE (strain TF18) or phyR together with chrR or rpoE/chrR. Following agents were used in zone inhibition assays: t-BOOH (white bars), methylene blue (black bars), diamide (dark grey bars), or paraquat (light grey bars). Error bars indicate the standard deviation of zones of inhibition from three biological replicates. According to Students t-test none of the changes between PhyR deletion strains and the parental strains is significant $(P \leq 0.05)$

mutant was complemented by a plasmid-encoded phyR gene (strain 2.4.1 $\triangle \mathrm{PhyR}$ (pBE::phyR eCFP)), survival was identical as for the wild type for both stresses (Additional file $4 \mathrm{~A}$ and $\mathrm{B}$ ).

We complemented these experiments by spread plating assays which confirmed a significant effect of PhyR on the survival in presence of SDS/EDTA or ethanol (Fig. 4c). We also included treatment with polymyxin that alters membrane permeability and the uncoupling reagent CCCP (carbonyl cyanide $m$-chlorophenyl hydrazone). The effect of the phyR mutation for these reagents was less pronounced than for SDS/EDTA or ethanol, nevertheless the survival rate in the mutant was significantly lower than in the wild type strain (Fig. 4).

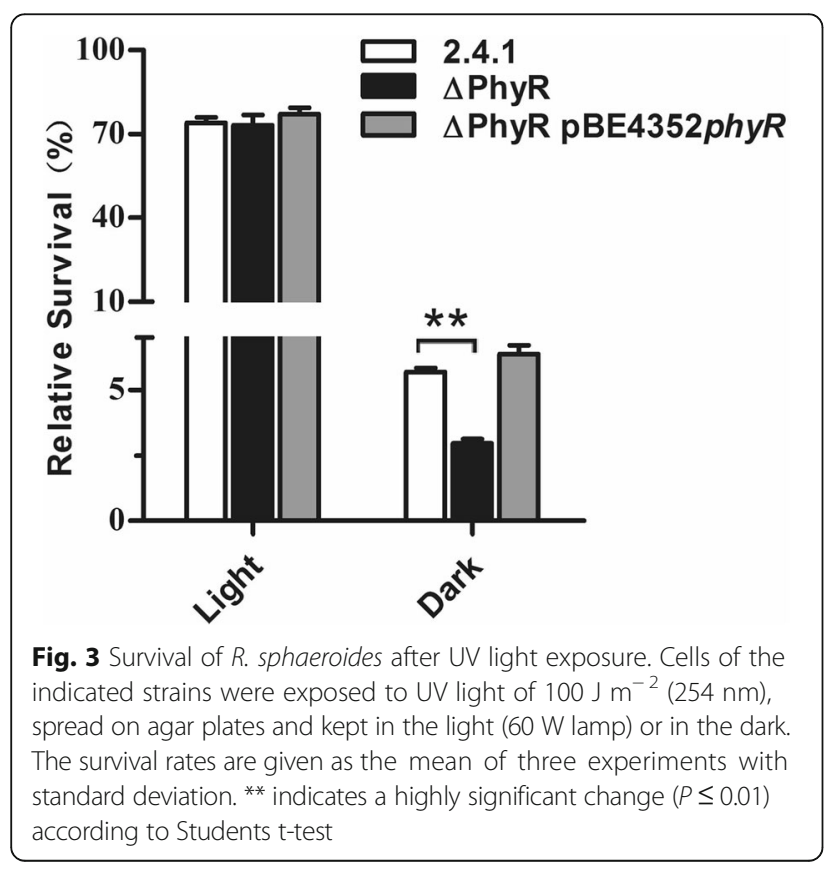

To test whether the effect of PhyR on membrane stress is mediated via the $\mathrm{RpoE} / \mathrm{ChrR}$ system we also constructed mutants lacking $\mathrm{ChrR}$ or ChrR/RpoE together with PhyR. The results clearly demonstrate that the effect on membrane stress is solely due to PhyR. Strains $\Delta$ ChrR and TF18 showed the same resistance to membrane stress as the wild type (Fig. 4).

\section{Effect of $R$. sphaeroides PhyR on RpoE-dependent gene activation}

RpoE (RSP_1092) of $R$. sphaeroides has an important function in the singlet oxygen stress response and also activates RpoHII in the general stress response. To elucidate a possible effect of PhyR on the activity of this sigma factor, we determined the $\beta$-galactosidase activity of a phrA-lacZ reporter plasmid. The phrA gene encodes a photolyase and is under direct control of RpoE. In strain TF18, which lacks RpoE and ChrR the $\beta$ galactosidase levels are very low in absence or presence of singlet oxygen (generated by addition of methylene blue and illumination) [30]. The $\Delta \mathrm{PhyR}$ deletion strain showed an increase in $\beta$-galactosidase activity after $1 \mathrm{~h}$ and $3 \mathrm{~h}$ of singlet oxygen stress, which was however less than observed for the wild type (Fig. 5a). As a consequence the wild type showed significantly higher activity after $1 \mathrm{~h}$ and $3 \mathrm{~h}$ of stress (Fig. 5a). phrA-lacZ activity was also monitored after treatment with $\mathrm{t}-\mathrm{BOOH}$ (Fig. $5 b)$. The $\beta$-galactosidase activity was significantly lower in the mutant after $1 \mathrm{~h}$ and $3 \mathrm{~h}$ of stress compared to the wild type. When the phyR gene was introduced into the strain that has phyR deleted from the chromosome, we observed $ß$-galactosidase activity similar or higher to that of the wild type, proving that altered RpoE activity in the mutant strain is indeed a consequence of the lack of PhyR.

Another gene, which is under direct control of RpoE encodes the small RNA Pos19 [32, 33]. Northern Blot 


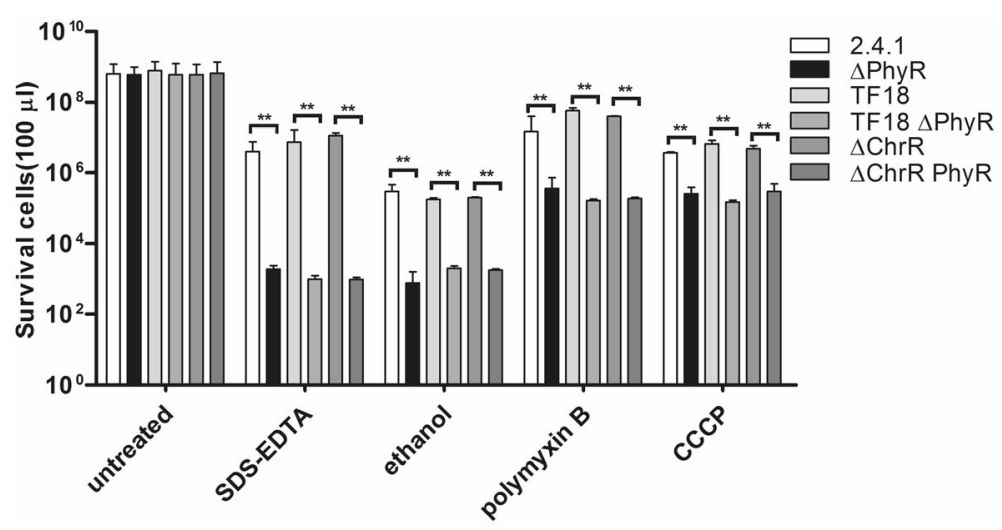

Fig. 4 Survival rates of $R$. sphaeroides strains as determined by spread plating assays and colony counting before and after 15 min of addition of $\operatorname{SDS}(0,015 \%)$ and EDTA $(30 \mathrm{mM}), 30 \mathrm{~min}$ of ethanol $(12 \%), 60 \mathrm{~min}$ of polymyxin $(2.5 \mathrm{mg} / \mathrm{ml})$, or $60 \mathrm{~min}$ of CCCP $(25 \mu \mathrm{M})$. Error bars indicate the standard deviation from three biological replicates. ${ }^{* *}$ indicates a highly significant change $(P \leq 0.01)$ according to Students t-test

analysis revealed a stronger induction of Pos19 in the wild type compared to the phyR mutant upon treatment with organic peroxide (Additional file 5).

\section{Effect of R. sphaeroides PhyR on stress-dependent mRNA levels}

Our data strongly indicate reduced RpoE-dependent gene activation in the strain lacking PhyR. Real time RTPCR analyses revealed that the rpoE mRNA level after treatment with $\mathrm{t}-\mathrm{BOOH}$ increases significantly stronger in the wild type and in the complemented mutant than in $\triangle$ PhyR (Fig. 6a). We also tested the effect of PhyR on some other genes with a role in the oxidative stress response in $R$. sphaeroides $[34,35]$. After $7 \mathrm{~min}$ of hydrogen peroxide the catA (RSP_2779) mRNA level for catalase increased significantly more in the PhyR mutant than in the wild type (Fig. 6c). For the mRNAs gloA (RSP_0392) and gloB (RSP_2294) for putative glyoxalases, higher induction in response to singlet oxygen was however observed for the wild type and the complemented
PhyR mutant compared to the PhyR mutant(Fig. 6b). The $g l o A$ and $g l o B$ genes are preceded by RpoHII-dependent promoters (14), while cat $A$ is not preceded by a promoter sequence for an alternative sigma factor. Since the rpoHII gene is under control of RpoE, changed expression levels of $g l o A$ and $g l o B$ mRNAs are most likely a consequence of the PhyR effect on RpoE activity.

We also followed rpoE mRNA levels in response to other stress conditions in the wild type and the $\triangle \mathrm{PhyR}$ mutant strain (Fig. 6c). A significant difference in rpoE mRNA level between the two strains was observed for singlet oxygen stress (methylene blue in the light). Diamide, heat, SDS/EDTA or ethanol had only minor effects on rpoE mRNA levels, while superoxide (paraquat treatment) and hydrogen peroxide resulted in increased $r p o E$ mRNA levels, which were slightly lower in the mutant, but these differences were statistically not significant (Fig. 6b). We also tested how diverse stresses affect phyR and RSP_1272 (- $\sigma$ (EcfG)) mRNA levels by real time RT PCR (Fig. 7). While singlet oxygen (methylene
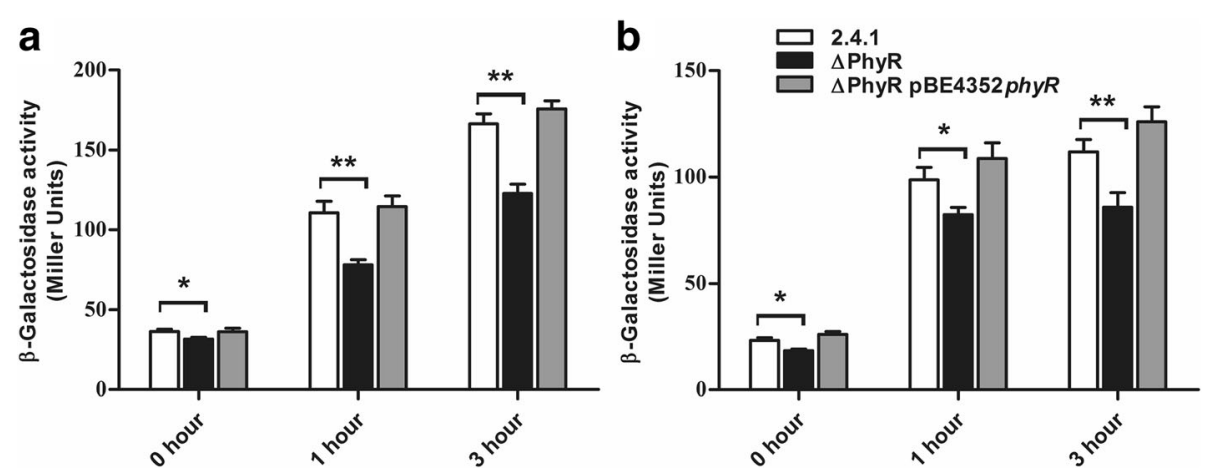

Fig. 5 -galactosidase actvity of R. sphaeroides strains harboring the reporter plasmid pPHUphrAlacZ. Cells were grown in aerobic conditions in the dark and were exposed to high light intensity $\left(880 \mathrm{~W} \mathrm{~m}^{-2}\right.$ ) and $50 \mathrm{nM}$ methylene blue (a) or to $360 \mu \mathrm{M}$ of t-BOOH (b) for the indicated time periods. The mean of three experiments and standard deviations are shown. ${ }^{*}$ indicates a significant change $(P \leq 0.05),{ }^{* *}$ indicates a highly significant change $(P \leq 0.01)$ according to Students t-test 


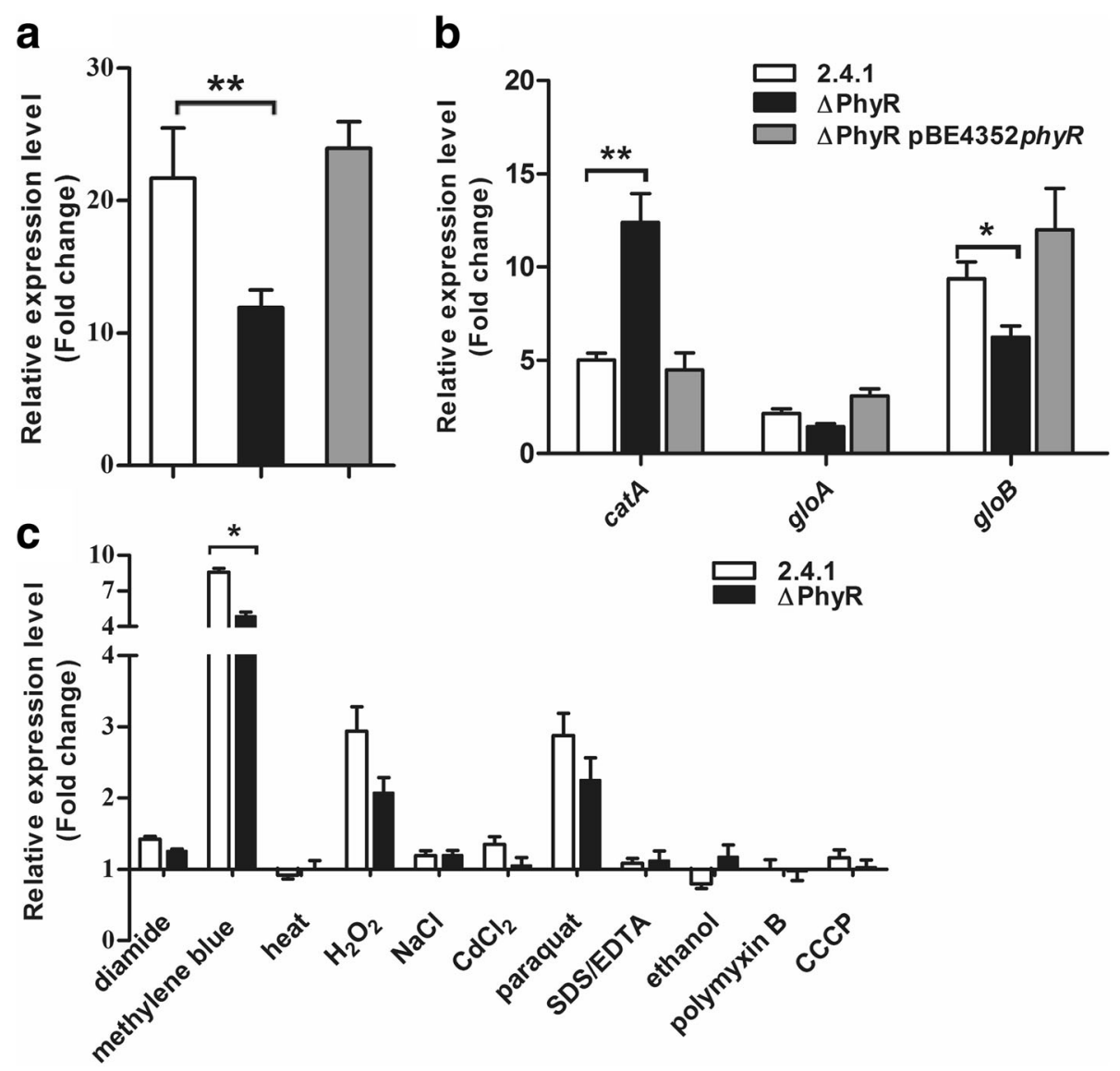

Fig. 6 a Levels of rpoE mRNA as determined by real time RT PCR in wild type 2.4.1 (white bars), phyR mutant (black bars) and complemented strain (grey bars). The fold change of 7 min versus 0 min under t-BOOH after normalization to rpoZ mRNA level is shown. $\mathbf{b}$ Levels of relative expression are shown for catA in response to hydrogen peroxide and gloA, glo $B$ in response to ${ }^{1} \mathrm{O}_{2}$ exposure in wild type 2.4.1 (white bars), phy $R$ mutant (black bars) and complemented strain (grey bars). Exposure to hydrogen peroxide or ${ }^{1} \mathrm{O}_{2}$ was performed for $7 \mathrm{~min}$. Values for relative expression levels represent the increase in gene expression compared to that of the control at time point 0 min and were normalized to mRNA levels determined for rpoZ. The mean of three experiments with standard deviation is shown. $\mathbf{c}$ Relative $r p o E$ mRNA levels under different stress conditions as determined by real time RT PCR in the wild type and the mutant lacking PhyR. * indicate a significant change $(P \leq 0.05),{ }^{* *}$ indicate a highly significant change $(P \leq 0.01)$ according to Students t-test

blue), superoxide (paraquat) and diamide resulted in 2-3 fold increase of the phyR mRNA level, none of the other stresses including membrane stress led to marked changes in phyR mRNA levels. Membrane stress was however the only stress factor that resulted in increased RSP_1272 mRNA levels and this increase is clearly dependent on PhyR.

\section{Discussion}

An important role for the PhyR-NepR- $\sigma$ (EcfG) cascade in regulating the general stress response was observed in several members of the Alphaproteobacteria [1]. Genes encoding proteins with good homology to the proteins of the PhyR-NepR- $\sigma$ (EcfG) cascade are also present in $R$. sphaeroides and are found in a similar chromosomal arrangement (Fig. 1). A similar role of PhyR in stress responses of $R$. sphaeroides as in other Alphaproteobacteria was conceivable. A $R$. sphaeroides strain lacking PhyR showed similar response as the parental wild type to singlet oxygen, hydrogen peroxide, superoxide, organic peroxides, diamide, heat or salt stress. We conclude that other proteins like the alternative sigma factors RpoE, RpoHI, and RpoHII are indeed the main regulators of the general stress response in $R$. sphaeroides.

Our data demonstrate however that expression of the $p h y R$ gene is modulated in response to some stresses and we found significant differences between wild type and mutant in response to membrane and UV stress. This suggests that PhyR has a more specialized role in $R$. sphaeroides. Up to now, the role of PhyR in stress responses was not analyzed for any member of the Rhodobacterales. Therefore it is possible that a more specialized function of PhyR is not limited to R. sphaeroides but may apply to a certain sub-branch of the Alphaproteobacteria. 


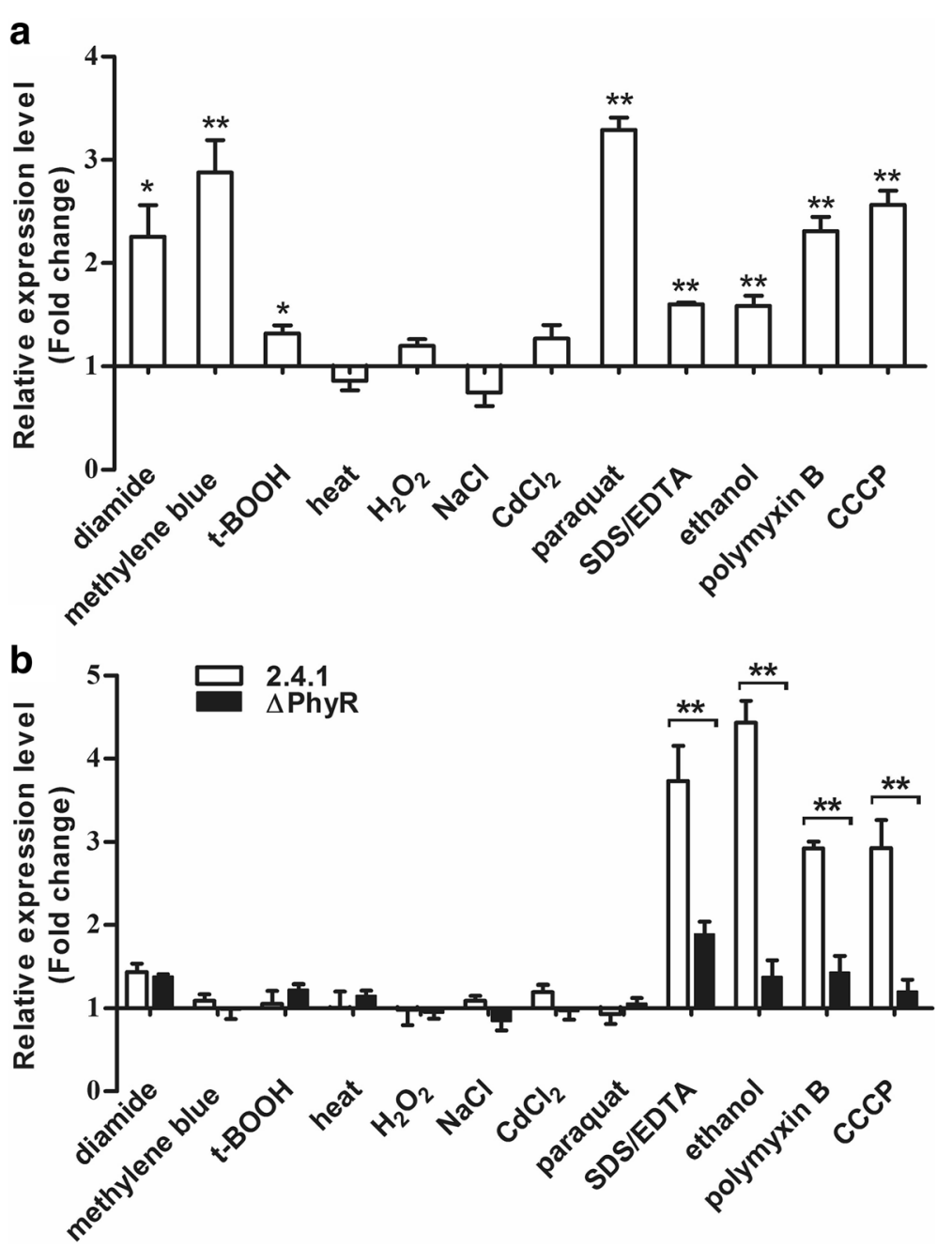

Fig. 7 Levels of phyR (a) and RSP_1272 (b) mRNAs under various stresses as determined by real time RT PCR. The following reagents were added to aerobic cultures at $\mathrm{OD}_{660}$ of 0.4 and samples were collected immediately before $(0 \mathrm{~min})$ and $7 \mathrm{~min}$ after addition: $0.2 \mu \mathrm{M}$ methylene blue and high light $\left(880 \mathrm{~W} \mathrm{~m}^{-2}\right.$ ), $360 \mu \mathrm{M} \mathrm{t}-\mathrm{BOOH}, 1 \mathrm{mM} \mathrm{H}_{2} \mathrm{O}_{2}, 250 \mu \mathrm{M}$ paraquat, $500 \mu \mathrm{M}$ diamide, $500 \mathrm{mM} \mathrm{NaCl}$, or $10 \mu \mathrm{M} \mathrm{CdCl}$. For heat shock, microaerobic cultures were shifted to $42^{\circ} \mathrm{C}$ at time 0 min or the following reagents were added: $0.005 \%$ SDS and $1 \mathrm{mM} \mathrm{EDTA,} 2.5 \%$ ethanol, $1 \mu \mathrm{g} / \mathrm{ml}$ polymyxin B or $10 \mu \mathrm{M} \mathrm{CCCP}$, and samples were collected at $0 \mathrm{~min}$ and $7 \mathrm{~min}$. The mean of three experiments with standard deviation is shown. ${ }^{*}$ indicate a significant change $(P \leq 0.05)$, ** indicate a highly significant change $(P \leq 0.01)$ according to Students t-test

While the phyR mRNA levels did not respond to membrane stress, the levels of the RSP_1272 mRNA encoding the $\sigma(\mathrm{EcfG})$ protein of the PhyR-NepR- $\sigma$ (EcfG) locus, was clearly increased in response to membrane stress, but not by other stress factors. This supports the view that the PhyR-NepR- $\sigma$ (EcfG) cascade in R. sphaeroides has a main role in the defense of membrane stress. Increased RSP_1272 mRNA levels were dependent on PhyR in agreement with signal transfer within the PhyRNepR- $\sigma$ (EcfG) cascade.

Furthermore our data provide clear evidence for an effect of PhyR on rpoE mRNA level and RpoE-dependent gene activation (Figs. 5, 6 and Additional file 5). Why is the influence of PhyR on RpoE activity not manifested as altered stress resistance in the mutant? In mutants lacking ChrR or RpoE and ChrR together (strain TF18) the change in rpoE mRNA level is of course much more pronounced than in the PhyR mutant under the tested conditions. $\triangle$ ChrR or TF18 mutants are clearly affected in stress resistance, but additional mutation of phyR did not increase this effect implying that PhyR can not even partially compensate the loss of these main regulators. Many investigations in the past have demonstrated that complex regulatory networks including protein and RNA regulators are involved in controlling and balancing stress responses [36-38]. The moderate changes of RpoE activity caused by the lack of PhyR may not be sufficient to cause a clear phenotype since compensation by other players in the regulatory network may take place. In $R$. sphaeroides the PhyR-NepR- $\sigma($ EcfG) cascade may 
also have a function in balancing some stress responses rather than triggering such responses. A cross talk of the PhyR-NepR- $\sigma$ (EcfG) cascade to the RpoE/ChrR system has not been reported for other Alphaproteobacteria to date.

\section{Conclusions}

Our results demonstrate that PhyR has no major role in the general stress response of the Alphaproteobacterium $R$. sphaeroides as reported before for other bacterial species $[1,39,40]$. We could attribute a role of PhyR in defense of membrane stress and survival of UV light in the dark in $R$. sphaeroides, supporting a more specialized function in this bacterium. PhyR has no major contribution to the complex regulatory network (e.g.: 8, 9, 15, 29, 30) of protein and sRNA regulators that control the oxidative stress response in $R$. sphaeroides.

\section{Additional files}

Additional file 1: Strains and plasmids (Table S1), Oligodeoxynucleotides (Table S2) used in this study. (PDF $163 \mathrm{~kb}$ )

Additional file 2: Schematic representation and RNA-seq read coverage of the phyR operon in Rhodobacter sphaeroides. Blue: Read coverage of the phyR operon in R. sphaeroides visualized by the Integrated Genome Browser. Black: Genes are represented by black boxes. The direction of the arrow indicates the direction of transcription. (PDF $66 \mathrm{~kb}$ )

Additional file 3: Growth of the Rhodobacter sphaeroides wild type 2.4.1 and various mutant strains after heat shock. Cultures were grown at $32{ }^{\circ} \mathrm{C}$ to exponential phase in microaerobic conditions and diluted to $\mathrm{OD}_{660}$ of 0.1 . For each strain $5 \mu \mathrm{l}$ of diluted culture were spread on agar plates and incubated under the indicated temperature in the dark. The agar plates incubated at $42{ }^{\circ} \mathrm{C}$ were shifted to $32{ }^{\circ} \mathrm{C}$ after $24 \mathrm{~h}$. (PDF $791 \mathrm{~kb}$ )

Additional file 4: Spot survival assays for $R$. sphaeroides and phy $R$ mutant after membrane stress. All strains were cultured to an $\mathrm{OD}_{660}$ of 0.5 in microaerobic condition. $5 \mu$ from consecutive 10 -fold dilutions were spotted onto agar plates before and after 15 and $30 \mathrm{~min}$ of SDS (0.015\%) and EDTA $(30 \mathrm{mM})$ treatment(A) or after 30 and $60 \mathrm{~min}$ of ethanol (12\%) treatment. (PDF $1323 \mathrm{~kb}$ )

Additional file 5: Northern blot analysis of Pos19. Cultures were treated with $\mathrm{t}-\mathrm{BOOH}$ and samples taken at time point 0 and $7 \mathrm{~min}$. Pos 19 bands were normalized to the $5 \mathrm{~S}$ rRNA and the calculated fold change is indicated. (PDF $669 \mathrm{~kb}$ )

\section{Abbreviations}

CCCP: Carbonyl cyanide $m$-chlorophenyl hydrazone; EcfG: Extracytoplasmic function sigma factor; t-BOOH: t-Butyl hydroperoxide; TSS: Transcriptional start sites; UV: Ultraviolet light; $\beta$-Gal: $\beta$-galactosidase

\section{Acknowledgements}

We thank A. Jäger for constructing the phyR mutant. Katrin Muller is acknowledged for help with northern blotting assays.

\section{Funding}

QL and TP were supported by fellowships from the Chinese Scholarship Council. The funding body did not contribute to the design of the study or to data collection, analysis, and interpretation or in writing the manuscript.

\section{Availability of data and materials}

All data generated and/or analyzed during the current study are included in this published article (and in its supplementary files). The RNA-seq data are available at the NCBI Gene Expression Omnibus database under accession number GSE71844. The datasets used and/or analyzed during the current study are available from the corresponding author on reasonable request.

\section{Authors' contributions}

QL was the main contributor to the experimental work. TP and GK contributed with the design of the study. GK drafted the manuscript. All authors approved the final version of the article.

Ethics approval and consent to participate

Not applicable

Consent for publication

Not applicable

\section{Competing interests}

The authors declare that they have no competing interests.

\section{Publisher's Note}

Springer Nature remains neutral with regard to jurisdictional claims in published maps and institutional affiliations.

\section{Author details}

${ }^{1}$ Institut für Mikrobiologie und Molekularbiologie, Interdiziplinäres Forschungszentrum, Justus-Liebig-Universität Giessen, Heinrich-Buff-Ring 26-32, 35392 Giessen, Germany. ${ }^{2}$ Present address: Department of Biology, Shantou University, Shantou, Guangdong, China.

Received: 21 September 2017 Accepted: 20 February 2018

Published online: 27 February 2018

\section{References}

1. Francez-Charlot A, Kaczmarczyk A, Fischer HM, Vorholt JA. The general stress response in Alphaproteobacteria. Trends Microbiol. 2015;23(3):164-71. https://doi.org/10.1016/j.tim.2014.12.006

2. Gourion B, Rossignol M, Vorholt JA. A proteomic study of Methylobacterium extorquens reveals a response regulator essential for epiphytic growth. Proc Natl Acad Sci U S A. 2006;103(35):13186-91. https://doi.org/10.1073/pnas. 0603530103

3. Gourion B, Francez-Charlot A, Vorholt JA. PhyR is involved in the general stress response of Methylobacterium extorquens AM1. J Bacteriol. 2008;190(3):1027-35. https://doi.org/10.1128/Jb.01483-07.

4. Alvarez-Martinez CE, Lourenco RF, Baldini RL, Laub MT, Gomes SL. The ECF sigma factor sigma(T) is involved in osmotic and oxidative stress responses in Caulobacter crescentus. Mol Microbiol. 2007;66(5):1240-55. https://doi.org/ 10.1111/j.1365-2958.2007.06005.x.

5. Sauviac L, Philippe H, Phok K, Bruand C. An extracytoplasmic function sigma factor acts as a general stress response regulator in Sinorhizobium meliloti. J Bacteriol. 2007:189(11):4204-16. https://doi.org/10.1128/Jb.00175-07.

6. Francez-Charlot A, Frunzke J, Reichen C, Ebneter JZ, Gourion B, Vorholt JA. Sigma factor mimicry involved in regulation of general stress response. Proc Natl Acad Sci U S A. 2009;106(9):3467-72. https://doi.org/10.1073/pnas. 0810291106.

7. Berghoff B, Klug G. Small RNAs with a role in the oxidative stress response of bacteria. In: Anita M, Wolfgang H, editors. Regulatory RNAs in Prokaryotes. FL, Springer Vienna; 2012. p. 1-14. https:/doi.org/10.1007/978-3-7091-0218-3_1.

8. Glaeser J, Nuss AM, Berghoff BA, Klug G. Singlet oxygen stress in microorganisms. Adv Microb Physiol. 2011;58:141-73. https://doi.org/10.1016/B978-0-12-381043-4. 00004-0.

9. Hess WR, Berghoff BA, Wilde A, Steglich C, Klug G. Riboregulators and the role of Hfq in photosynthetic bacteria. RNA Biol. 2014;11(5):413-26. https:// doi.org/10.4161/rna.28035

10. Anthony JR, Warczak KL, Donohue TJ. A transcriptional response to singlet oxygen, a toxic byproduct of photosynthesis. Proc Natl Acad Sci U S A. 2005;102(18):6502-7. https://doi.org/10.1073/pnas.0502225102.

11. Glaeser J, Zobawa M, Lottspeich F, Klug G. Protein synthesis patterns reveal a complex regulatory response to singlet oxygen in Rhodobacter. J Proteome Res. 2007;6(7):2460-71. https://doi.org/10.1021/pr060624p.

12. Nuss AM, Glaeser J, Klug G. RpoH(II) activates oxidative-stress defense systems and is controlled by RpoE in the singlet oxygen-dependent response in Rhodobacter sphaeroides. J Bacteriol. 2009:191(1):220-30. https://doi.org/ 10.1128/Jb.00925-08. 
13. Nuss AM, Glaeser J, Berghoff BA, Klug G. Overlapping alternative sigma factor regulons in the response to singlet oxygen in Rhodobacter sphaeroides. J Bacteriol. 2010;192(10):2613-23. https://doi.org/10.1128/Jb.01605-09.

14. Dufour YS, Imam S, Koo BM, Green HA, Donohue TJ. Convergence of the transcriptional responses to heat shock and singlet oxygen stresses. PLoS Genet. 2012;8(9):e1002929. https://doi.org/10.1371/journal.pgen.1002929.

15. Billenkamp F, Peng T, Berghoff BA, Klug G. A cluster of four homologous small RNAs modulates C1 metabolism and the pyruvate dehydrogenase complex in Rhodobacter sphaeroides under various stress conditions. J Bacteriol. 2015;197(10):1839-52. https://doi.org/10.1128/JB.02475-14.

16. Newman JD, Anthony JR, Donohue TJ. The importance of zinc-binding to the function of Rhodobacter sphaeroides ChrR as an anti-sigma factor. J Mol Biol. 2001;313(3):485-99. https://doi.org/10.1006/jmbi.2001.5069.

17. Anthony JR, Newman JD, Donohue TJ. Interactions between the Rhodobacter sphaeroides ECF sigma factor, sigma(E), and its anti-sigma factor, ChrR. J Mol Biol. 2004;341(2):345-60. https://doi.org/10.1016/j.jmb.2004.06.018.

18. Nuss AM, Adnan F, Weber L, Berghoff BA, Glaeser J, Klug G. DegS and RseP homologous proteases are involved in singlet oxygen dependent activation of RpoE in Rhodobacter sphaeroides. PLoS One. 2013;8(11):e79520. https:// doi.org/10.1371/journal.pone.0079520.

19. Remes B, Berghoff BA, Forstner KU, Klug G. Role of oxygen and the OxyR protein in the response to iron limitation in Rhodobacter sphaeroides. BMC Genomics. 2014;15:794. https://doi.org/10.1186/1471-2164-15-794.

20. Hubner P, Masepohl B, Klipp W, Bickle TA. nif gene expression studies in Rhodobacter capsulatus: $n t r C$-independent repression by high ammonium concentrations. Mol Microbiol. 1993;10(1):123-32.

21. Prentki $P$, Krisch HM. In vitro insertional mutagenesis with a selectable DNA fragment. Gene. 1984;29(3):303-13.

22. Janzon L, Lofdahl S, Arvidson S. Evidence for a coordinate transcriptional control of alpha-toxin and protein-a synthesis in Staphylococcus-Aureus. FEMS Microbiol Lett. 1986;33(2-3):193-8

23. Remes B, Rische-Grahl T, Muller KMH, Forstner KU, Yu SH, Weber $L$, et al. An $\mathrm{RpoHI}$-dependent response promotes outgrowth after extended stationary phase in the Alphaproteobacterium Rhodobacter sphaeroides. J Bacteriol. 2017;199(14) https://doi.org/10.1128/JB.00249-17.

24. Pfaffl MW. A new mathematical model for relative quantification in real-time RT-PCR. Nucleic Acids Res. 2001;29(9):e45. https://doi.org/10.1093/nar/29.9.e45.

25. Hubner P, Willison JC, Vignais PM, Bickle TA. Expression of regulatory nif genes in Rhodobacter-Capsulatus. J Bacteriol. 1991;173(9):2993-9.

26. Miller JH. Experiments in molecular genetics. Cold Spring Harbor, N.Y: Cold Spring Harbor Laboratory; 1972.

27. Bastiat B, Sauviac L, Bruand C. Dual control of Sinorhizobium meliloti RpoE2 sigma factor activity by two PhyR-type two-component response regulators. J Bacteriol. 2010;192(8):2255-65. https://doi.org/10.1128/Jb.01666-09.

28. Bourret RB. Receiver domain structure and function in response regulator proteins. Curr Opin Microbiol. 2010;13(2):142-9. https://doi.org/10.1016/j. mib.2010.01.015.

29. Sharma CM, Hoffmann S, Darfeuille F, Reignier J, Findeiss S, Sittka A, et al. The primary transcriptome of the major human pathogen Helicobacter pylori. Nature. 2010;464(7286):250-5. https://doi.org/10.1038/nature08756.

30. Hendrischk AK, Braatsch S, Glaeser J, Klug G. The phrA gene of Rhodobacter sphaeroides encodes a photolyase and is regulated by singlet oxygen and peroxide in a sigma(E)-dependent manner. Microbiology. 2007;153(Pt 6): 1842-51. https://doi.org/10.1099/mic.0.2006/004390-0.

31. von Zadow A, Ignatz E, Pokorny R, Essen LO, Klug G. Rhodobacter sphaeroides CryB is a bacterial cryptochrome with (6-4) photolyase activity. FEBS J. 2016; 283(23):4291-309. https://doi.org/10.1111/febs.13924

32. Berghoff BA, Glaeser J, Sharma CM, Vogel J, Klug G. Photooxidative stress-induced and abundant small RNAs in Rhodobacter sphaeroides. Mol Microbiol. 2009;74(6): 1497-512. https://doi.org/10.1111/j.1365-2958.2009.06949.x

33. Muller KM, Berghoff BA, Eisenhardt BD, Remes B, Klug G. Characteristics of Pos19 - a small coding RNA in the oxidative stress response of Rhodobacter sphaeroides. PLoS One. 2016;11(9):e0163425. https://doi.org/10.1371/journal. pone. 0163425

34. Zeller T, Klug G. Detoxification of hydrogen peroxide and expression of catalase genes in Rhodobacter. Microbiology. 2004;150(Pt 10):3451-62. https://doi.org/10.1099/mic.0.27308-0.

35. Berghoff BA, Konzer A, Mank NN, Looso M, Rische T, Forstner KU, et al. Integrative "omics"-approach discovers dynamic and regulatory features of bacterial stress responses. PLoS Genet. 2013;9(6):e1003576. https://doi. org/10.1371/journal.pgen.1003576.
36. Mank NN, Berghoff BA, Hermanns YN, Klug G. Regulation of bacterial photosynthesis genes by the small noncoding RNA PcrZ. Proc Natl Acad Sci U S A. 2012;109(40):16306-11. https://doi.org/10.1073/pnas.1207067109.

37. Storz G, Vogel J, Wassarman KM. Regulation by small RNAs in bacteria: expanding frontiers. Mol Cell. 2011;43(6):880-91. https://doi.org/10.1016/ j.molcel.2011.08.022.

38. Waters LS, Storz G. Regulatory RNAs in bacteria. Cell. 2009;136(4):615-28. https://doi.org/10.1016/j.cell.2009.01.043.

39. Staron A, Mascher T. General stress response in alpha-proteobacteria: PhyR and beyond. Mol Microbiol. 2010;78(2):271-7. https://doi.org/10.1111/j.13652958.2010.07336x

40. Fiebig A, Herrou J, Willett J, Crosson S. General stress signaling in the Alphaproteobacteria. Annu Rev Genet. 2015;49:603-25. https://doi.org/ 10.1146/annurev-genet-112414-054813.

\section{Submit your next manuscript to BioMed Central and we will help you at every step:}

- We accept pre-submission inquiries

- Our selector tool helps you to find the most relevant journal

- We provide round the clock customer support

- Convenient online submission

- Thorough peer review

- Inclusion in PubMed and all major indexing services

- Maximum visibility for your research

Submit your manuscript at www.biomedcentral.com/submit
Biomed Central 